\title{
The Building Extraction Based on Object Oriented Classification Method in High Vegetation Coverage Area
}

\author{
Baoying Ye1, Nisha Bao ${ }^{2}$ \\ ${ }^{1}$ School of Land Science and Technology, China University of Geosciences, Beijing, China \\ ${ }^{2}$ School of Resources and Civil Engineering, Northeastern University, Shenyang, China \\ Email: yebaoying@cugb.edu.cn
}

How to cite this paper: Ye, B.Y. and Bao, N.S. (2019) The Building Extraction Based on Object Oriented Classification Method in High Vegetation Coverage Area. Journal of Computer and Communications, 7 , 9-16.

https://doi.org/10.4236/jcc.2019.77002

Received: March 6, 2019

Accepted: July 7, 2019

Published: July 10, 2019

\begin{abstract}
Quickly extraction of building information technology is an important application in urban development planning, electronic information, national defense and others. This paper takes Landsat- 8 multispectral and panchromatic data as data source, using the local variance method to select the optimal segmentation scale, normalized difference vegetation index (NDVI) and the normalized building index (NDBI) and panchromatic brightness value of an object oriented classification rule extraction. The high vegetation coverage area of buildings, and through the spatial relationships and distinguishing feature of collections of buildings independent buildings and villages. The results showed that Google earth high resolution image analysis and accuracy evaluation. the results of the extraction based on the overall accuracy of village extraction was $83 \%$, the accuracy of extraction of independent buildings was $70 \%$, according to the L8 remote sensing data, object oriented classification method can quickly and accurately extract the high vegetation coverage area of the building.
\end{abstract}

\section{Keywords}

Oriented Classification, High Vegetation Coverage Area, Building

\section{Introduction}

The built up areas is important components of national and regional geographical database. Up-to-date spatial information of built-up feature on urban sprawl is needed at local and regional scale. The location and area of built-up strongly correlate with urban plan, resource management and military reconnaissance. 
The extraction of built-up information technology has an important application in urban development planning, electronic information, national defence and others [1] [2]. The earth observation satellite imagery serves as a promising source to extract the land use/land cover classes. However, the extraction of urban built-up from remote sensing data is using traditional human interpretation way and pixel-based approach. Compared to traditional approach, the extracted objects by an object-based image analysis (OBIA) approach are more homogeneous than by pixels based approach and are closer to a visual human interpretation with high classification accuracy [3]. The OBIA's results (extracted objects) can be integrated within vector GIS more easily than classified raster maps. Furthermore, OBIA approach utilizing a rule based integration and directly builds into the existing knowledge pool, which can be applied on different satellite images. Recent developments in OBIA based on multi-resolution segmentation have revolutionized the processing of high resolution sensed data by offering effective computer-assisted classification techniques that come close to the quality of manual photo-interpretation, whilst being much faster, cheaper and more reproducible [4]. Some successful built-up area extractions have been obtained with this approach [5] [6]. Therefore, the aim of this study is to automatic and quick extract the freestanding built-up area and villages from China-Myanmar frontier with high vegetation coverage area using OBIA method based on Landsat-8 imagery. The local variance method is conduced to indicate the optimal segmentation scale in OBIA classification. The spectral and geometry feature characteristic were selected to establish OBIA classification rules.

\section{Data and Method}

\subsection{Study Area Description and Remote Sensing Data}

The study area is located in mountainous area, southwestern of Lincang Yunnan province near the China-Myanmar frontier (Figure 1). The landsat-8 multi-spectral and panchromatic images acquired on the 7th March of 2015 were used with track number of 131-33. The multi-spectral image is $30 \mathrm{~m}$ spatial resolution with 8 ands, and $15 \mathrm{~m}$ spatial resolution for panchromatic image. The images for experiment was subset with 1024 pixel $^{*} 1024$ pixel $^{*}$. The preprocessing steps included radiometric correction and geo-reference with the average root mean square error below 1 pixel. The high resolution image was downloaded from Google earth as the reference data for classification accuracy assessment.

\subsection{Object-Oriented Classification Method}

The template is used to format your paper and style the text. All margins, column widths, line spaces, and text fonts are prescribed; please do not alter them. You may note peculiarities. For example, the head margin in this template measures proportionately more than is customary. This measurement and others are deliberate, using specifications that anticipate your paper as one part of the 


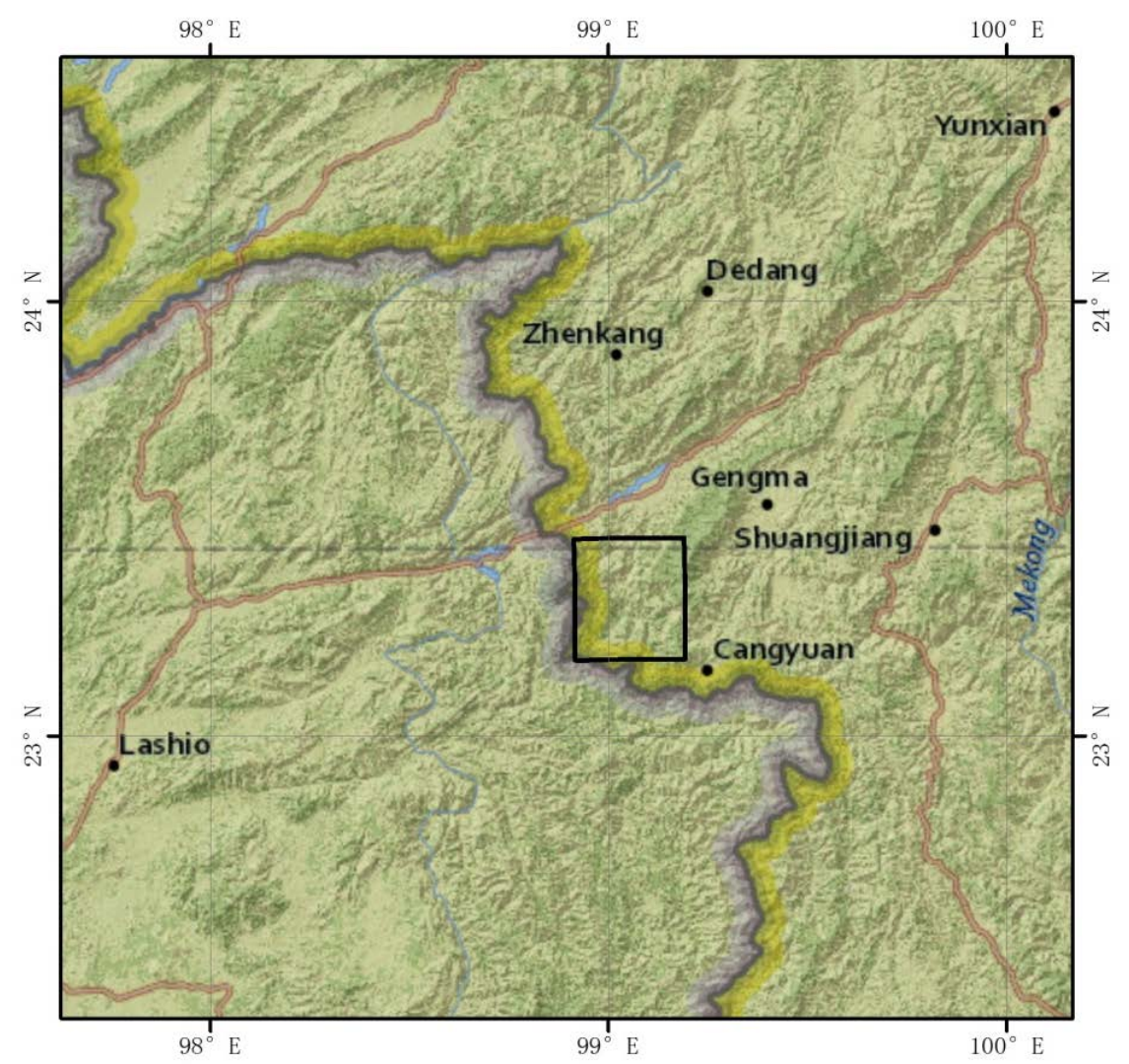

Figure 1 . The location of study area.

entire journals, and not as an independent document. Please do not revise any of the current designations.

1) Multi-scale segmentation

Multi-scale image segmentation is a critical procedure that affects classification quality [4]. The basic theory is the region merging method. The image segmentation is started by merging a single pixel with the pixel around it in a high homogeneity. When growing the size of a segment, its SD (standard deviation) increases continuously, up to the point that it matches the object in the real world. In numerous iterative steps, smaller image-objects are merged into larger ones. The segmentation layers are different by setting the kinds of threshold for different features. The ESP tool calculates the local variance as the mean standard deviation of objects for each object level obtained through segmentation. The ESP tool provides a fast estimation of scale parameters for multi-resolution segmentation in the Definiens software environment [7]. The graphics of the local variance are used to evaluate the appropriate scale parameters, relative to data properties of the scene [8]. The peaks in the local variance graph indicate the object levels at which the image can be segmented in the most appropriate manner, relative to data properties at the scene level. To assess the dynamics of local variance from an object level to another, we use a measure called rate of change (ROC). Scale parameters represented by these break points are evaluated with regard to their representation of different feature types by using visual assess- 
ment.

2) Image feature

a) Normalized Difference Build-up Index (NDBI)

NDBI (Normalized Difference Build-up Index, NDBI) is based on the difference in reflectance between two spectral bands. The gray value of city is highest among the features, as the spectral range from the near infrared to shortwave infrared. There is a strong reflection of shortwave infrared and a strong absorption of near infrared at the city surface, which is used to classify the city from the image [9]. The NDBI was calculated following general equation:

$$
\mathrm{NDBI}=\frac{\rho_{\text {SWIR }}-\rho_{\text {NIR }}}{\rho_{\text {SWIR }}+\rho_{\text {NIR }}}
$$

where the $\rho_{N I R}$ and $\rho_{S W I R}$ are the mean surface reflectance in the near-infrared and shortwave infrared spectral regions.

b) Normalized Difference Vegetation Index (NDVI)

NDVI (Normalized Difference Vegetation Index, NDVI) is based on the difference in reflectance between two spectral bands [10].It can be calculated following general equation:

$$
\mathrm{NDVI}=\frac{\rho_{N I R}-\rho_{R E D}}{\rho_{N I R}+\rho_{R E D}}
$$

where $\rho_{N I R}$ and $\rho_{N E D}$ are the surface reflectance in the near-infrared and red spectral regions.

As the NDVI is less than 0 , it represents the land surface is covered by the water or snow. As the NDVI equal to 0 , the bare soil and rock can be identified. The NDVI can be lager with the higher fractional coverage, as NDVI over to 0 . The NDVI is widely used to predict the crop condition and monitor the vegetation with its susceptibility to green vegetation

\section{Object-Oriented Classification Rules}

The local variance method was used to calculate the segmentation optimization scale in the object-based analyses (Figure 2 \& Figure 3). The peaks in the local

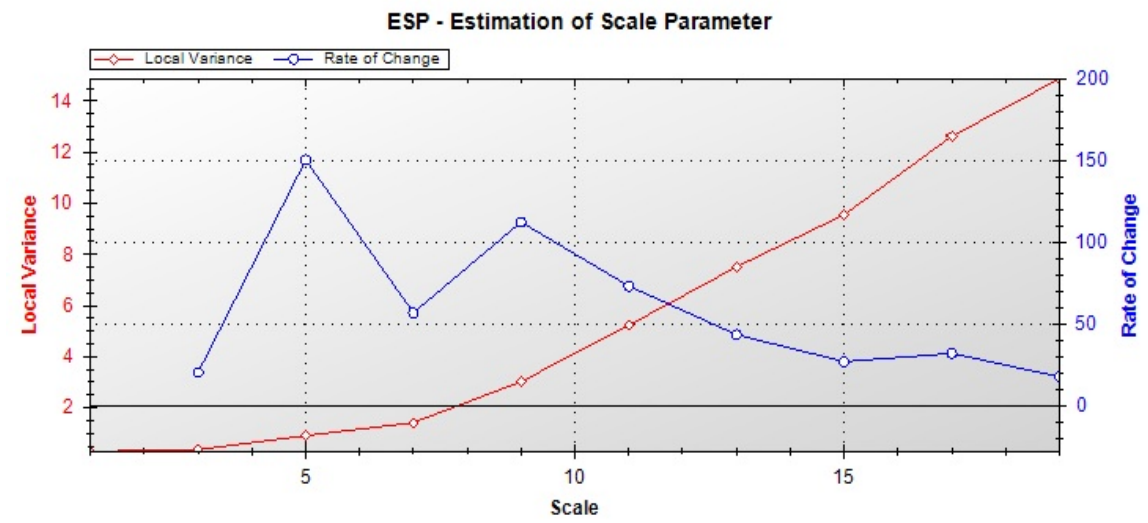

Figure 2. The local variance at multi-scale segmentation. 
variance graph indicate the object levels at which the image can be segmented in the most appropriate manner, relative to data properties at the scene level. The results of the ESP tool indicated significant peak within the local variance rate of change curve at scale parameters of 5 .

The NDBI, NDVI and the brightness value of panchromatic images were used to classify the study area using the object-based analyses. The vegetation can be classified with the NDVI over 0.2 , as the city and bare soil can be identified using the NDBI and brightness value. The country and freestanding can be separated with the geometrical characteristic and the distance to field (Figure 4).

Before you begin to format your paper, first write and save the content as a separate text file. Keep your text and graphic files separate until after the text has been formatted and styled. Do not use hard tabs, and limit use of hard returns to only one return at the end of a paragraph. Do not add any kind of pagination anywhere in the paper. Do not number text heads-the template will do that for you.

Finally, complete content and organizational editing before formatting. Please take note of the following items when proofreading spelling and grammar:

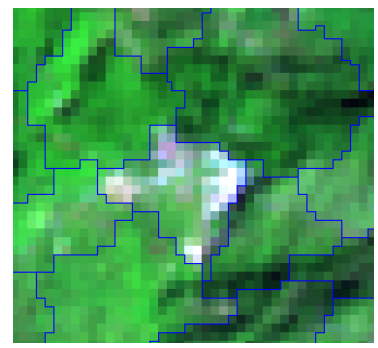

(a)

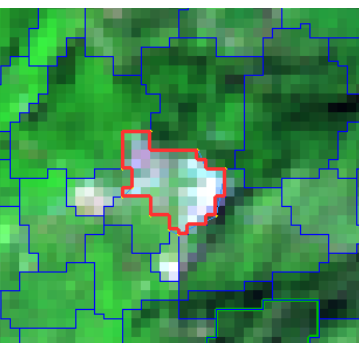

(b)

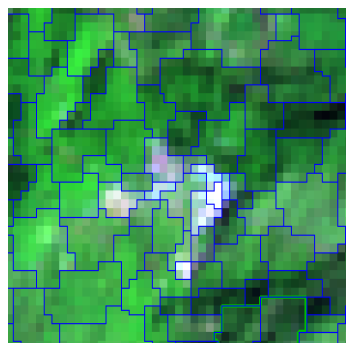

(c)

Figure 3. The segmentation results from multi-scale segmentation. (a) Scale =7; (b) Scale $=5$; (c) Scale $=3$.

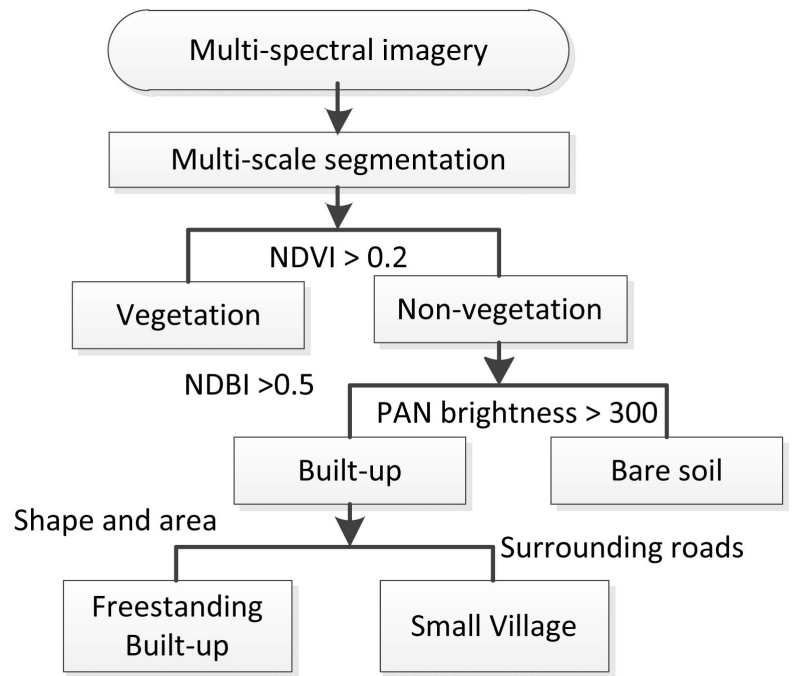

Figure 4. The object-oriented classification rules. 


\section{Classification Results and Accuracy Assessment}

As shown in Figure 5, the number of 149 villages was extracted using object-oriented classification method. There are 36 freestanding built-up lands with average area $7903.75 \mathrm{~m}^{2}$. The overall accuracy of the villages and freestanding built-up lands is $83.33 \%$ and $70.59 \%$ respectively. The area of freestanding built-up less than $3600 \mathrm{~m}^{2}$ cannot be identified with the limited of the spatial resolution of the Landsat image (Figures 6-8).

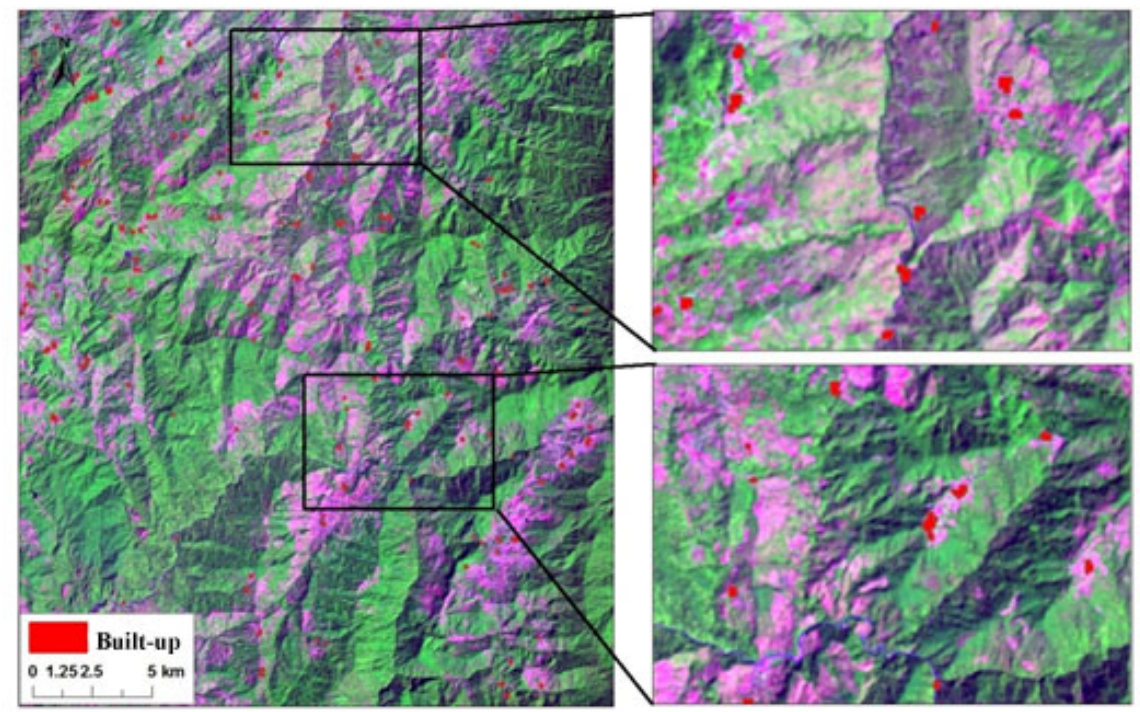

Figure 5. The object-oriented classification results.
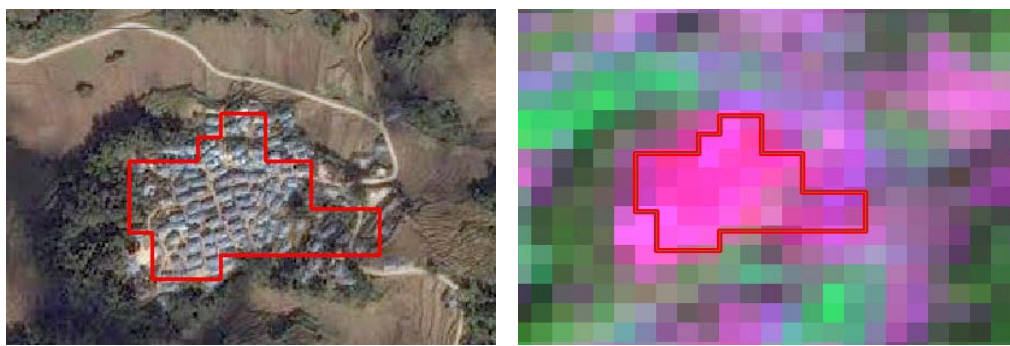

Figure 6. The classified village overlay in the Google earth (left) and Landsat imagery (right).
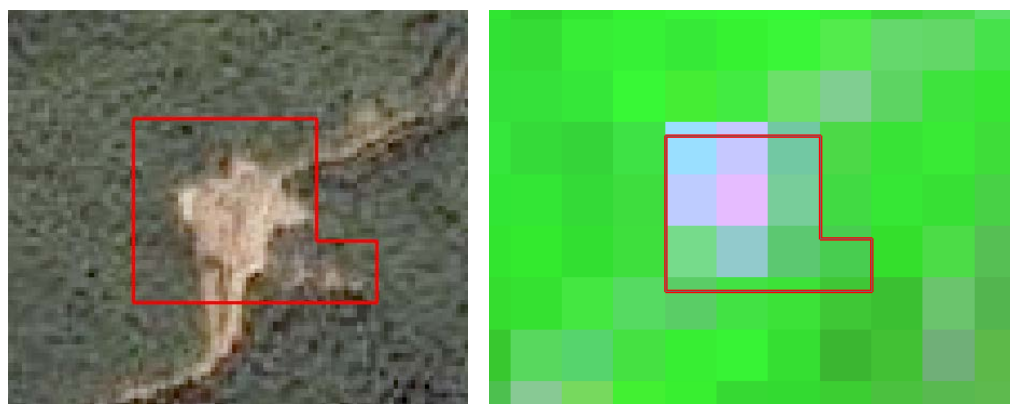

Figure 7. The freestanding built-up at upslope hill overlay in the Google earth (left) and Landsat imagery (right). 

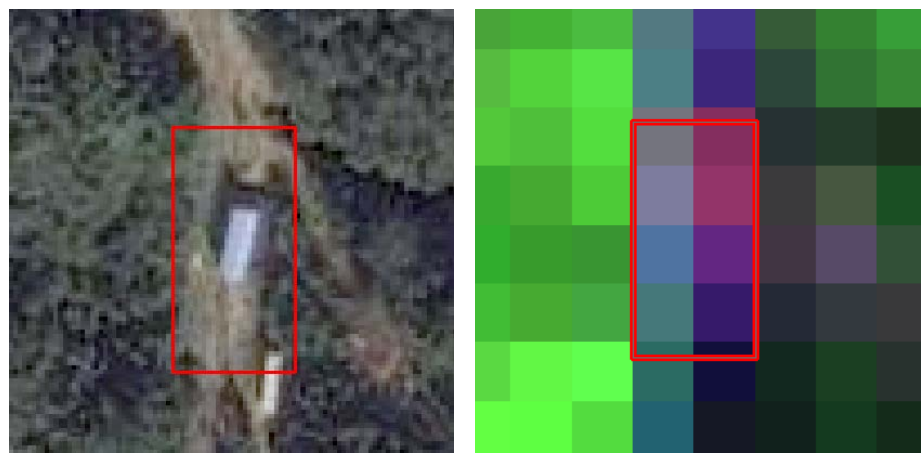

Figure 8. The freestanding built-up at the top of hill overlay in the Google earth (left) and Landsat imagery (right).

\section{Conclusion}

This study proposed a new framework that combines object-level classification to detect built-up land in the high fraction coverage from high-spatial resolution remote sensing images. The local variance was conducted to indicate the optimal segmentation scale of 5 can produce high classification accuracy in object-based classification. Furthermore, the NDVI, NDBI and brightness value was selected to establish the classification rules. Most of the built-up area was scattered in the large area of high vegetation Coverage Mountain, which resulted in the low classification accuracy using the traditional classification methods. The object-oriented method is a robust and fast-way for built-up area extraction in high vegetation coverage area. Our study can provide the basic data for village plan and boundary safety.

\section{Conflicts of Interest}

The authors declare no conflicts of interest regarding the publication of this paper.

\section{References}

[1] Du, S., Zhang, F. and Zhang, X. (2015) Semantic Classification of Urban Buildings Combining VHR Image and GIS Data: An Improved Random Forest Approach. ISPRS Journal of Photogrammetry and Remote Sensing, 105, 107-119.

https://doi.org/10.1016/j.isprsjprs.2015.03.011

[2] Durieux, L., Lagabrielle, E. and Nelson, A. (2008) A Method for Monitoring Building Construction in Urban Sprawl Areas Using Object-Based Analysis of Spot 5 Images and Existing GIS Data. ISPRS Journal of Photogrammetry and Remote Sensing, 63, 399-408. https://doi.org/10.1016/j.isprsjprs.2008.01.005

[3] Bhaskaran, S., Paramananda, S. and Ramnarayan, M. (2010) Per-Pixel and Object-Oriented Classification Methods for Mapping Urban Features Using Ikonos Satellite Data. Applied Geography, 30, 650-665.

https://doi.org/10.1016/j.apgeog.2010.01.009

[4] Blaschke, T. (2010) Object Based Image Analysis for Remote Sensing. ISPRS Journal of Photogrammetry and Remote Sensing, 65, 2-16.

https://doi.org/10.1016/j.isprsjprs.2009.06.004 
[5] Belgiu, M. and Dr Gut, L. (2014) Comparing Supervised and Unsupervised Multiresolution Segmentation Approaches for Extracting Buildings from Very High Resolution Imagery. ISPRS J Photogramm Remote Sens, 96, 67-75.

https://doi.org/10.1016/j.isprsjprs.2014.07.002

[6] Tomljenovic, I., Tiede, D. and Blaschke, T. (2016) A Building Extraction Approach for Airborne Laser Scanner Data Utilizing the Object Based Image Analysis Paradigm. International Journal of Applied Earth Observation and Geoinformation, 52, 137-148. https://doi.org/10.1016/j.jag.2016.06.007

[7] Dragut, L., Tiede, D. and Levick, S.R. (2010) ESP: A Tool to Estimate Scale Parameter for Multiresolution Image Segmentation of Remotely Sensed Data. International Journal of Geographical Information Science, 24, 859-871. https://doi.org/10.1080/13658810903174803

[8] Kim, M., Madden, M. and Warner, M. (2008) Estimation of Optimal Image Object Size for the Segmentation of Forest Stands with Multispectral IKONOS Imagery. In: Blaschke, T., Lang, S. and Hay, G.J., Eds., Eds., Object-Based Image Analysis, Springer, Berlin, 292-307. https://doi.org/10.1007/978-3-540-77058-9_16

[9] Zha, Y., Gao, J. and Ni, S. (2010) Use of Normalized Difference Built-Up Index in Automatically Mapping Urban Areas from TM Imagery. International Journal of Remote Sensing, 24, 583-594. https://doi.org/10.1080/01431160304987

[10] Tucker, C.J. (1979) Red and Photographic Infrared Linear Combinations for Monitoring Vegetation. Remote Sensing of Environment, 8, 127-150.

https://doi.org/10.1016/0034-4257(79)90013-0 